\title{
The Characteristics and Path Analysis on Public Opinion Spread of Public Emergency Events in Social Media Age
}

\author{
Zuowei Zhao \\ Institute of Media \\ Inner Mongolia University for Nationalities \\ Inner Mongolia, China
}

\begin{abstract}
In recent years, the public emergencies have frequently occurred in China. The rapid development of social media has provided a natural platform in which the public opinion spread and diffuse. The intertwining of real society and cyberspace and the dual form of citizens and netizens, which make the structural contradictions and social negative emotions accumulated in the transition period appear in a more intense and complete way. In the era of social media, public opinion of emergency events show a new feature, the transmission path of it presents a new form.This article will analyze and demonstrate it.
\end{abstract}

Keywords-social media age; public opinion; public emergency events;spread path analysis

\section{The TyPe OF PUBlic EMERGENCY EVENTS}

Public emergencies refer to natural disasters, accident disasters, public health events and social public security incidents that occur, cause or may cause serious social harm, and need to be dealt with by emergency measures. Public emergencies are characterized by sudden, harmful, public, complex and persistent.

The development stage of these events includes four stages: latency, high tide, remission and extinction. The specific types of public emergencies are two types :one is caused by natural disasters, the other is the unique "sudden public events" in the network era, which some accidental "small event" evolved into influential public events involving a wide range with the network amplification and instantly detonated public opinion

\section{The SPREAd FEATURES OF PUBlic EMERGENCY OPINION}

A. Public Opinion Events Touch Internet Users Common Psychology Social Common Emotions and Event Resonance so that Emergencies on the Internet Quickly Ferment for Public Events

Social common feelings is the reason of public opinion development, but also the power of public opinion diffusion.Now the prevalence of common emotions in society will become the internal driving force that a constant transmission of events and spread of their public opinion.
Public opinion events related to the vital interests of the people.Through the network public opinion diffusion,an ordinary social event can spread easily to arouse public sympathy.Internet users express and vent emotions via these events, which gradually into a more consistent opinion public opinion coax.

The development of communication technology has promoted the openness and transparency of information. Many hidden social problems have been demonstrated through cyberspace, and the social media platform has enabled people's emotions to converge and ferment.

Emotion itself has obvious law of the same frequency resonance, Internet users in the social interaction will form a series of specific emotions. Due to the role of social emotions, public opinion of specific events will accelerate to spread, and opinion gap has intensified in the proliferation of public opinion,such as "Heyi hotel girl attacked"incident, "Wei Zexi"incident, "Leiyang's die"incident and other public safety events involved public interests occurred in 2016. The common point of these events is triggered by the common people's psychological sympathy, causing public psychology panic.

B. One Public Opinion Incident can Trigger A Number of Similar Opinion Events Occurred by "Butterfly Effect", and the Effect of Public Opinion Filled and

Superposition Is Obvious

Through the media coverage,the public opinion events with different time and places, such as official conflict, doctor-patient conflict, environmental pollution, form a unique impression in the audience minds, showing a common factor.

Through the continuous media coverage,these events will be strengthened and cured in audience cognitive psychology, so as to form a certain cognitive model.In the event of similar incidents, this cognitive model of Internet users will play an important role in the development of public opinion. More and more emergencies themselves have shown a "chain" of the characteristics which stimulate specific cognitive patterns of internet users each other, and the public 
opinion changes into the formation of surging waves in the diffuse constantly superimposed to strengthen.

\section{Public Opinion Polarization Based on Emotional Expression Has Become the Main Form of Network Public Opinion}

At present, the right of citizens and enthusiasm to participate in social and public governance have enhanced. The network has become the source of public opinion. However, due to the low media literacy of overall Chinese netizens, the new media environment anonymity and Internet information fission characteristics, the Internet users get the "pre-screen security" and "do not have to take responsibility for the indifference". Irrational mind of Internet users has been filled with the field of the network public opinion.

The emotional expression of public opinion can easily lead to group unconscious "extreme resonance". According to " China Internet Development Statistics Report" released by China Internet Network Information Center in January 2017, the majority of China's Internet users at present is young people , 10-39-year-old groups accounted for $73.7 \%$ of the total netizens, Which 20-29 age group of Internet users accounted for the highest, up to $30.3 \%$.

Young netizens have strong express desire in the network, and show the characteristics of extreme views, extreme expression in the public opinion field.In some public events, they wait for the truth of events for the lack of patience, do not dig deeper reason behind the incident, only base on the incident surface information directly to judge, and express their views, and then seek other Internet users' support, which is one of the reasons led to "public opinion reversal" phenomenon.

In addition, when some people have views of polarization and extreme in the field of public opinion, public opinion is extremely easy to extreme in the view of the collision and confrontation. Some negative public opinion events break out in the group polarization, and format collective unconscious "extreme resonance" phenomenon. The depersonalization of social networks is conducive to the formation of group identity, while eliminating individual differences, but also expanding the differences between groups, so that the network public opinion continues to develop on the direction of the original bias, ultimately showing a polarization of opinion.

\section{D. "Information Cocoon Room"Created by Social Media Make "No Principle of Sympathy for the Weak" Emotional Spread}

American scholar R.Sunstein put forward the concept of "information cocoon room" in his work"information utopia". The public's information needs are often followed by interest, and will shackles themselves in the cocoon-like "cocoon room" over time. R.Sunstein believe that there is the existence of the limitations of the network, which customizes the information at the same time, but also filters and isolates the other views. So the Internet users enhance psychological hardening on a problem or a group of people. In the conflict between civil and public or between social different groups, the people tend to this psychological solidification into one side to the weak groups without the principle of sympathy.

\section{E. The Network Generalization Label Makes Public Opinion to the Trend of Radical}

With the opening of the Internet and the continuous differentiation of the interests in China, the expression of individual ideas shows a wide range of tendencies, putting a profound impact on the direction of public opinion.

Listening to public opinion is one important factor that the enlightened government must consider in the process of governance decision-making. Internet public opinion has become an important force influencing the government's public decision-making.

Although the Internet provides a free public platform for Internet users, but under the influence of group polarization, Internet users are more inclined to accept point of view from the "like-minded" .The "one-way thinking" in social psychology makes "dissident" view filtered out, following with the formation of a certain consensus within the group,and the expression of people is more extreme. The groups were affixed the network generalization label each other, and the result of cross-team work is public opinion tear, and will deepen the social division and ideological polarization.

\section{F. The Interweave of the Irrational and Public Opinion Rationality Is Another One Characteristic of Public Opinion in Social Media}

Internet and new media provide a natural platform for personal opinion and interest demands conveyed, and promote the expression of public issues and the process of social and democratic. However, the freedom of view expresses makes cyberspace as a place of emotional ventures, where contains a lot of irrational remarks and emotions. The network space has become a platform filled with emotional infection and public opinion coax .

In some unexpected public events, the incidents show up an irrational situation at the beginning. some Internet users express the disclosure of dissatisfaction with the community through the event, releasing the negative emotions of the usual accumulation to the government or government officials.

In this way, for the lack of independent thinking ability, Internet users become "gangster", the rational network public opinion and the irrational camp shift each other with the development of the event,and continue to divide, the network public opinion field shows barren and confused state.

\section{SPREAD PATH ANALYSIS OF PUBLIC OPINION OF PUBLIC EMERGENCY EVENTS}

\section{A. Public Opinion Ferment through the Formation of New Media Platform, and the traditional media follow-up Communicate It}

As the network and new media communication characteristics and media attributes, public emergencies often originate from micro-blog, WeChat and other social new media platform at first.Through fissile spread in the 
socialization of new media, public opinion quickly proliferate, to be the formation of hot public events at last.

The traditional media then report the issue following up the new media, further increasing the spread of public opinion of the event. This transmission path, is the main way of the current public emergencies public opinion spreading. According to the People's Network public opinion monitoring room statistics, $80 \%$ public hot events originated in the network and new media in 2016.

\section{B. The Sudden Public Events Spread through the Traditional Media, then by New Media}

As the traditional mainstream media in the sudden public events reporting have the source advantages. Some natural disasters, major accidents and other major emergencies will be reported through traditional media, then the new media, especially social medias follow the spread of public opinion presented by the traditional. The network public opinion shows obvious characteristics from the traditional mass medias to the new medias.

In addition, in some public emergencies spread, the mainstream media and online social media will also synchronously generate their own public opinion, and make the formation of "two public opinion field".Nan Zhenzhong, former editor-in-chief in Xinhua News Agency, note that two public opinion field exist in China. One is "mainstream media public opinion field", which contains the party newspaper, national television and national news agency, the other is called"civil opinion field" relying on personal communicate, especially on the Internet.

The Internet has become the "ideological and cultural information distribution center and the amplifier of the public opinion ", and is rewriting the new pattern of guide of public opinion .

In some unexpected public events, the network rumors, network violence, public opinion polarization and other phenomena, make a serious deterioration of the network public opinion. In this context, only the mainstream media clarify the truth in a timely manner to the public, and eliminate network rumors and other false public opinion information, effectively guide the healthy and orderly development of public opinion and promote social harmony and stability.

\section{CONCLUSION}

Social media has spawned the new generation and communication feature of public opinion. Especially in public emergencies, public opinion has shown lower ignition temperature and not controllable feature, brings certain negative influence to the network public opinion ecology and social stability. How to master these characteristics and use the corresponding rules of public opinion to circumvent these negative information has become a major proposition of network governance and social governance in our country.

In some public emergencies spread, the mainstream media and online social media will also synchronously generate their own public opinion, and make the formation of "two public opinion field". Nan Zhenzhong, former editor- in-chief in Xinhua News Agency, note that two public opinion field exist in China. One is "mainstream media public opinion field", which contains the party newspaper, national television and national news agency, the other is called"civil opinion field" relying on personal communicate, especially on the Internet.

The Internet has become the "ideological and cultural information distribution center and the amplifier of the public opinion ", and is rewriting the new pattern of guide of public opinion .

In some unexpected public events, the network rumors, network violence, public opinion polarization and other phenomena, make a serious deterioration of the network public opinion. In this context, only the mainstream media clarify the truth in a timely manner to the public, and eliminate network rumors and other false public opinion information, effectively guide the healthy and orderly development of public opinion and promote social harmony and stability.

\section{REFERENCES}

[1] China Internet Network Information Center. Thirty-seventh statistical report on the development of China's Internet.http://www.cnnic.net.cn/hlwfzyj/hlwxzbg/hlwtjbg/201701/t2 0170122_66437.htm, 2017-01-22/2017-03-04.

[2] Yang Guang. "Social media polarization and consensus". Journalism and communication research, 2016, (2).65-68. 